Ann. rheum. Dis. (1956), 15, 26.

\title{
PULMONARY CHANGES IN DISSEMINATED LUPUS ERYTHEMATOSUS
}

\author{
BY \\ J. D. AITCHISON AND A. WYNN WILLIAMS \\ From the Royal Infirmary, Aberdeen, and the Department of Pathology, Aberdeen University
}

(RECEIVED FOR PURLICATION DECEMBER 16, 1955)

Pulmonary manifestations in the "diffuse collagen diseases" are said to be commoner than is generally believed and may overshadow the more typical features (Ellman and Cudkowicz, 1954). Over 80 years ago Kaposi (1872) mentioned intercurrent pneumonia in his original account of the visceral lesions of disseminated lupus erythematosus (D.L.E.). Osler (1904) described a case with prolonged consolidation of the lower lobe of the left lung. Subsequent accounts have affirmed the frequency of pleurisy in D.L.E. and, to a lesser degree, of pneumonia.

Until recently, pulmonary changes in D.L.E. have been regarded as the result of secondary bacterial invasion. The possibility of a primary, noninfective involvement of lung was, however, discussed by Klemperer, Pollack, and Baehr (1941), who were impressed by "waxing and waning bronchopneumonia" imperfectly reflected in the post-mortem findings. The number of observations on this aspect of the disease is still relatively meagre. In the three cases of the disease described here, the lungs were examined with special care.

\section{Case Reports}

Case 1, an unmarried domestic servant, aged 43, had been a healthy woman until August, 1952, when she developed pains in the joints of her hands, severe enough to cause her to be off work for 2 months. During the previous year she had noticed that her fingers became very cold and white in cold weather. In August, 1953, her shoulders and wrists became painful and stiff; later, other limb joints were affected, she felt exhausted, and pyrexia was noted. She was treated with penicillin and sodium salicylate, without apparent improvement. She was admitted to the Royal Infirmary, Aberdeen, in October, 1953.

Examination.-She was an obese, lethargic woman, temperature was $102^{\circ} \mathrm{F}$., head hair scanty, skin notably dry and scaly.

Joints.-Movements of the left shoulder, right elbow, knees and ankles were painful and restricted, and the ankles were slightly swollen.
Heart.-The cardiac apex beat could not be felt, there was an apical systolic murmur (Grade III), and the blood pressure was $140 / 90$.

Lungs.-Rales were heard over both lungs, particularly at the bases.

Urine.-A trace of albumin and a few red and white blood cells.

Blood.-Erythrocyte sedimentation rate (Westergren) $135 \mathrm{~mm} . / \mathrm{hr}$. Wassermann reaction, gonococcal complement-fixation test, Paul Bunnell, and routine agglutination tests were all negative. No cold agglutinins found in the blood. Haemoglobin $8 \cdot 2 \mathrm{~g}$. per cent.

R.B.C. $2 \cdot 89$ millions per c.mm.

Colour index 0.94 .

W.B.C. 4,800 per c.mm.

Differential count essentially normal.

Plasma proteins 7.7 g. per cent., albumin $4 \cdot 46 \mathrm{~g}$. per cent., globulin $3 \cdot 24 \mathrm{~g}$. per cent.; blood urea $20 \mathrm{mg}$. per cent.; serum alkaline phosphatase 5 units.

No abnormality in sternal marrow or cerebrospinal fluid.

Histology.-On 29.10 .53 a section of skin from the thigh showed hyperkeratosis, and mild atrophy of the epidermis; there was no evidence of disturbance of collagen.

Radiology. $-X$ rays of skull, spine, pelvis, and abdomen revealed no significant abnormality. $X$ ray of chest (20.10.53) showed that the transverse diameter of the heart was increased, and the left dome of the diaphragm was somewhat elevated.

Electrocardiogram (26.10.53). - Only sinus tachycardia (Fig. 1a, opposite).

Progress.-During the first week in hospital the patient's temperature varied between $100^{\circ}$ and $102^{\circ} \mathrm{F}$. Thereafter, there was intermittent low grade pyrexia for 3 weeks. The pain in the joints gradually diminished. The erythrocyte sedimentation rate (Westergren) was always above $100 \mathrm{~mm} . / \mathrm{hr}$.

$X$ ray of the chest (11.11.53) showed heart displaced slightly to left, left dome of diaphragm elevated, linear opacity above left costophrenic angle, consistent with pulmonary infarction, and minimal evidence of a pleural effusion.

On 16.11.53 ACTH was given by intramuscular injection; $25 \mathrm{mg}$. 6-hrly for 2 days, $25 \mathrm{mg}$. 8-hrly for 3 days, and $25 \mathrm{mg}$. twice daily for 7 days. At the end of this course the erythrocyte sedimentation rate had fallen to $46 \mathrm{~mm}$. $/ \mathrm{hr}$, but a week later it was $116 \mathrm{~mm}$. $/ \mathrm{hr}$. 
On 28.11.53 the patient complained of numbness in the feet and signs of neuritis of both lateral popliteal nerves gradually developed.

On 30.12.53 pyrexia recurred and rales were heard at the left lung base. A further chest $x$ ray showed an ill-defined opacity in the same region. During January, 1954, there was pain and stiffness of the shoulders, the erythrocyte sedimentation rate continued above $100 \mathrm{~mm}$./hr., there were occasional small spikes of temperature, the urine contained a small number of red and white cells, and L.E. cells were demonstrated in the peripheral blood.

On 6.2.54 a second course of ACTH was started, with the same dosage as before. On 11.2.54, after 5 days of this treatment, the blood pressure had risen to 205/120 from the usual level of about $140 / 90$, and peripheral oedema developed. ACTH was therefore discontinued immediately, and 2 days later (13.2.54) the blood pressure was $132 / 70$, and the erythrocyte sedimentation rate $73 \mathrm{~mm} . / \mathrm{hr}$.

Despite the rise in blood pressure, the patient improved in quite a remarkable degree and by 19.2.54 was up and walking about the ward. She was then sent to a small hospital near her home, and a month later, seemed to be further improved, being less easily tired and able to move about more freely, though there was still stiffness and pain in the right shoulder, and the erythrocyte sedimentation rate was $112 \mathrm{~mm} . / \mathrm{hr}$.

She returned home and was not seen again for nearly 8 months. She had continued to improve gradually throughout the summer and was able to do light tasks in the house until the end of August, 1954. Then she had become breathless, which she attributed to having "caught cold". The breathlessness had become steadily worse until she was distressed lying in bed. She had developed a cough and at times was troubled with wheezing. There had been no haemoptysis or chest pain. She had lost her appetite and lassitude had become severe.

Examination (1.10.54).-She was orthopnoeic, the neck veins were filled one inch above the clavicles, as she reclined at $45^{\circ}$, the lips were slightly cyanosed, there was sacral oedema, and the fingers were a bluish-red colour, especially around the nail beds.

Heart.-Blood pressure 130/86, heart sounds quiet, and only a faint systolic murmur could be heard.

Lungs.-At the lung bases, the respiratory murmur was diminished, and the percussion note impaired, and there were abundant rales.

Liver.-The liver edge was felt three fingerbreadths below the right costal margin.

Urine.-A moderate number of red blood corpuscles and a small amount of albumin.

Blood.-Haemoglobin $11 \cdot 2$ g. per cent., blood film normal, erythrocyte sedimentation rate 107 $\mathrm{mm}$./hr, plasma proteins $7 \cdot 87 \mathrm{~g}$. per cent.

Radiology. $-X$ ray of chest showed enlargement of cardiac shadow, the contour suggesting that pericardial effusion was present.

Electrocardiogram (Fig. 1b).-Marked right axis deviation. In lead aVR, $R$ wave $5 \mathrm{~mm}$. in height,

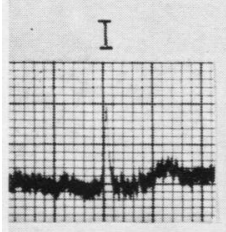

OVR

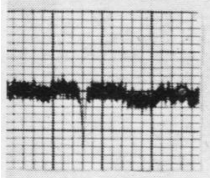

VI

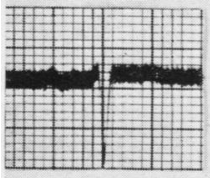

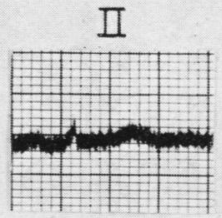

$\triangle V L$

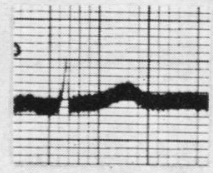

V3

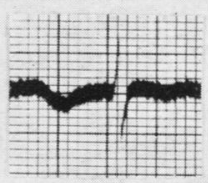

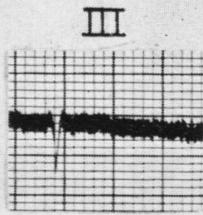

oVF

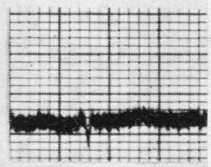

V5

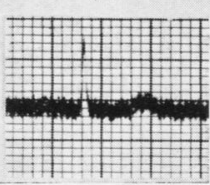

Fig. 1(a).-Electrocardiogram in October, 1953, showing no significant abnormality. There is left axis deviation.

and $\mathbf{S}$ wave absent; $\mathbf{S}$ wave now diminished in lead $\mathrm{V} 1$ and present in V5. Although the $R$ waves in the praecordial leads were small, these changes from the tracing of October, 1953, were taken to indicate hypertrophy of the right ventricle and raised the possibility of involvement of the pulmonary vessels by the disease process.

Therapy.-The patient was treated with salt restriction, digitalis, and mercuramide (Neptal). The signs of congestive cardiac failure lessened somewhat but breathlessness remained severe. A purpuric eruption appeared

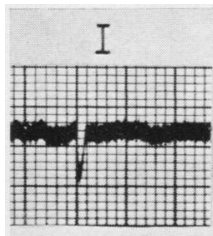

OVR

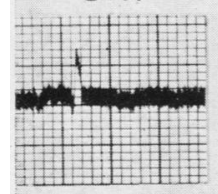

VI

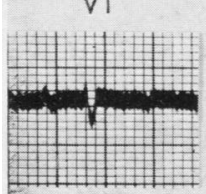

Fig. 1(b).-Electrocardiogram in October, 1954, showing development of marked right axis deviation and a tall $R$-wave in
of hypertrophy of right ventricle.

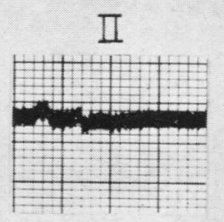

OVL

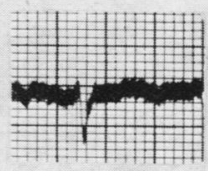

V3
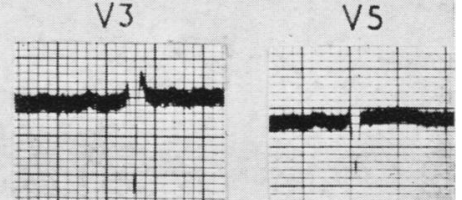

aVF

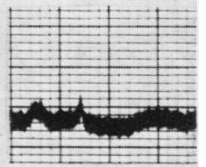

V5

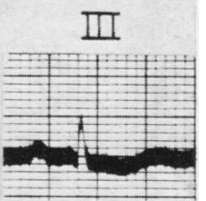

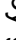

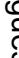


on her limbs. She was given chloroquin sulphate (Noviquin) $200 \mathrm{mg}$. twice daily, but she developed diarrhoea and the drug was discontinued.

Radioscopy (3.11.54) showed evidence of a small pericardial effusion. The respirations became still more rapid and distressed, and on 8.11 .54 at 11 a.m. pericardial aspiration was performed and $120 \mathrm{ml}$. strawcoloured fluid was removed. The procedure was uneventful, but there was no apparent lessening of breathlessness thereafter.

Death.-The patient's condition changed little throughout the day, but at 8 p.m. she became acutely distressed and markedly cyanosed. Despite resuscitative measures, her pulse became imperceptible and she died in a few minutes.

Post-mortem Examination (carried out 16 hours after death).-The body was that of a slightly obese adult female, height $1.6 \mathrm{~m}$. (5 ft. 2 in.), weight $66 \mathrm{~kg}$. (145 lb.). There was marked cyanosis of the head, neck, and hands. Purpuric spots were numerous on the limbs and the skin of the lower limbs was dry and scaly.

There was generalized dilatation of the heart $(420$ g.), also a healed verrucous endocarditis of the mitral, aortic, and pulmonary valves. In the right ventricle the muscle was markedly hypertrophied and ante-mortem thrombus was adherent to the endocardium. Fibrous adhesions and a serofibrinous effusion $(200 \mathrm{ml}$.) were present in the pericardial sac. Numerous fibrous adhesions and

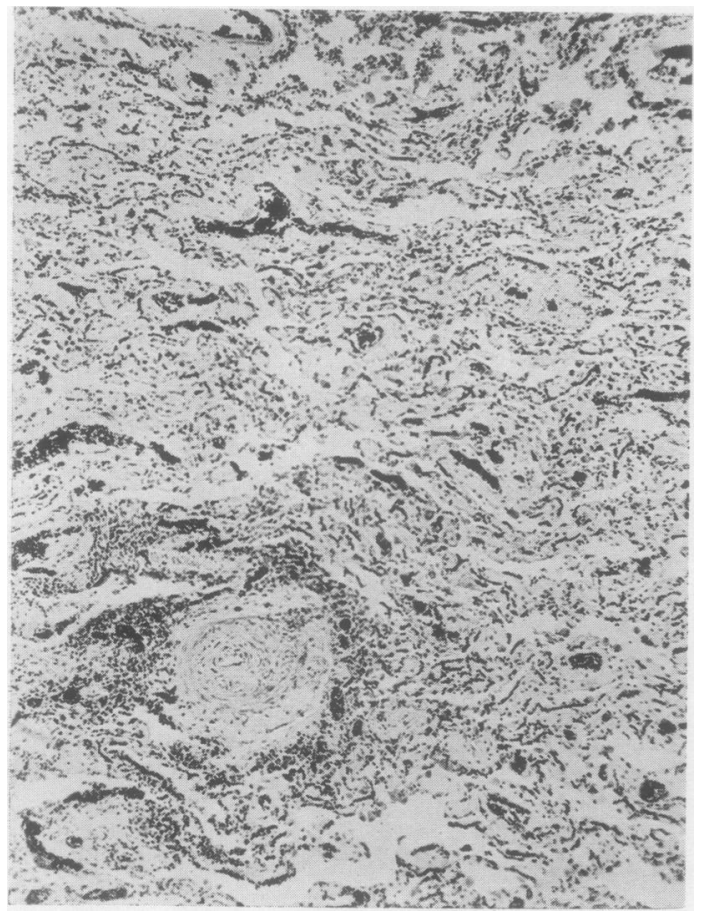

Fig. 2.-Collapsed portion of lung showing interstitial fibrosis and fibrinoid degeneration of an arteriole.

Haematoxylin and eosin $(\times 60)$. small serous effusions were found in the pleural sacs. $\frac{.}{3}$ The lungs showed diffuse vascular congestion and $\square$ oedema, also small scattered foci of collapse. The o? liver $(1,700 \mathrm{~g}$.), spleen $(180 \mathrm{~g}$.), and kidneys (combined weight $360 \mathrm{~g}$.) showed chronic venous congestion. A small serous ascites was present. The thyroid $(12 \mathrm{~g}$.) was small and partially fibrosed. The right adrenal ( 3 g.) was small, but the left (7 g.) was normal in size. The brain $\left(1,500 \mathrm{~g}\right.$.) was $\frac{\bar{c}}{\overrightarrow{0}}$ oedematous.

Histology.

Lungs.-These were congested and oedematous, के and contained widely-distributed small foci of $\vec{O}$ collapse, some with interstitial fibrosis (Fig. 2). Fibrinoid change of the intima, media, or whole $\vec{\omega}$ thickness of the wall was conspicuous in most $\stackrel{\sigma}{\circ}$ smaller arteries and arterioles, both pulmonary and bronchial (Figs 3 and 4). In the affected vessels degenerate nuclei were often prominent in the wall $\vec{G}$ (Fig. 5) and invariably there was mural infiltration with large and small mononuclear cells and poly- $\vec{\sim}$ morphonuclear leucocytes, mostly neutrophils. In o other small arteries and arterioles, the intima or else 을 the whole wall was thickened by layers of collagen (Fig. 6), while some arteries showed both intimal $\bar{z}$ fibrinoid change and fibrosis of the remainder of the wall. The lumen of the vessels with these various changes was narrowed, often considerably. A rare finding in the small arteries was occlusion of the $\vec{\theta}$ lumen by ante-mortem thrombus, with or without recanalization (Fig. 7). Small haemorrhages were seen in various parts of the lungs, but infarcts were

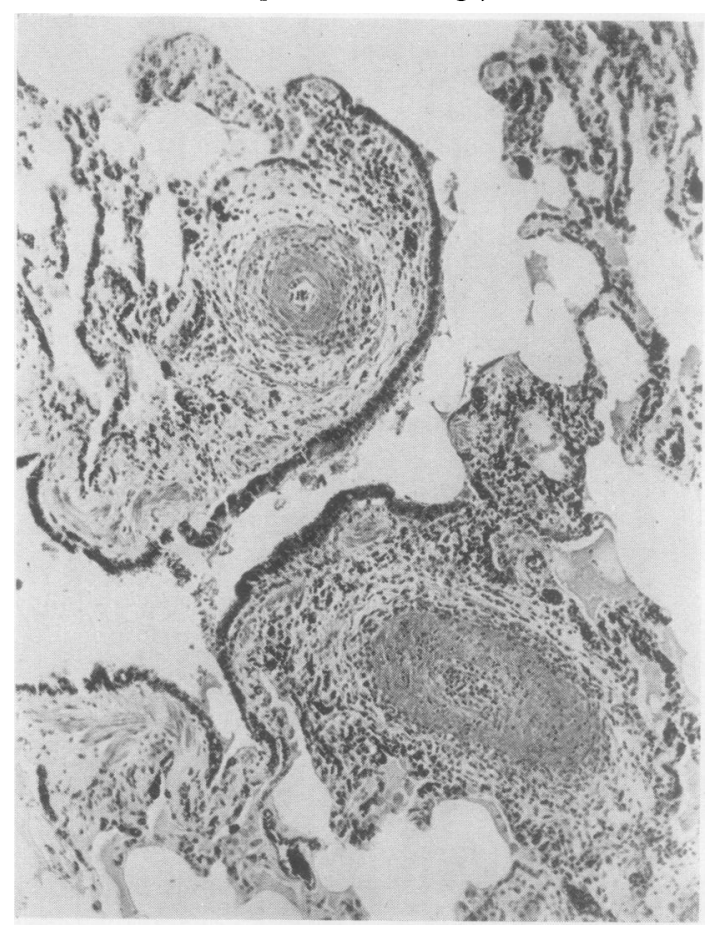

Fig. 3.-Fibrinoid degeneration in pulmonary arterioles, also perivascular leucocytosis.

Haematoxylin and eosin $(\times 60)$. 


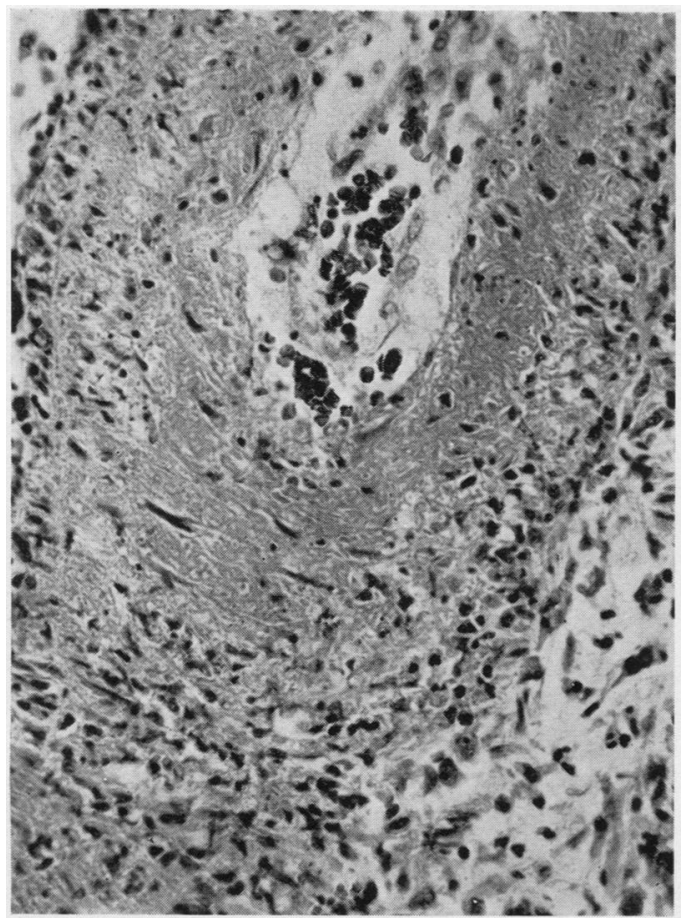

Fig. 4.-Fibrinoid degeneration in pulmonary artery. Haematoxylin and eosin $(\times 280)$.

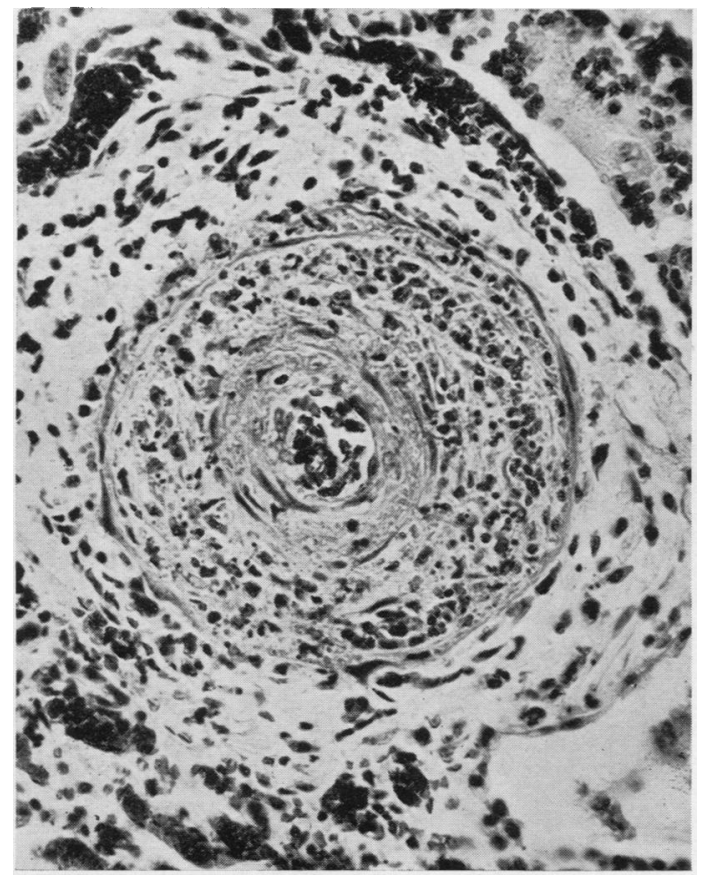

Fig. 5.-Fibrinoid pulmonary artery showing notable intramural nuclear degeneration and leucocytosis, also perivascular leucocytosis. Haematoxylin and eosin $(\times 280)$.

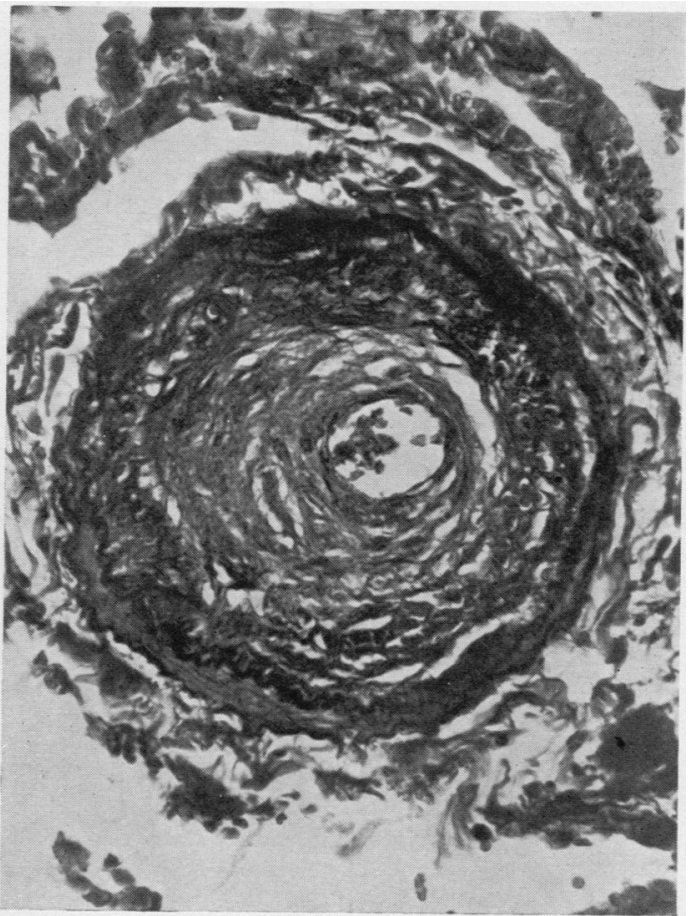

I Fig. 6.-Intimal fibrosis in pulmonary artery. Verhoeff-Van Gieson's stain $(\times 280)$.

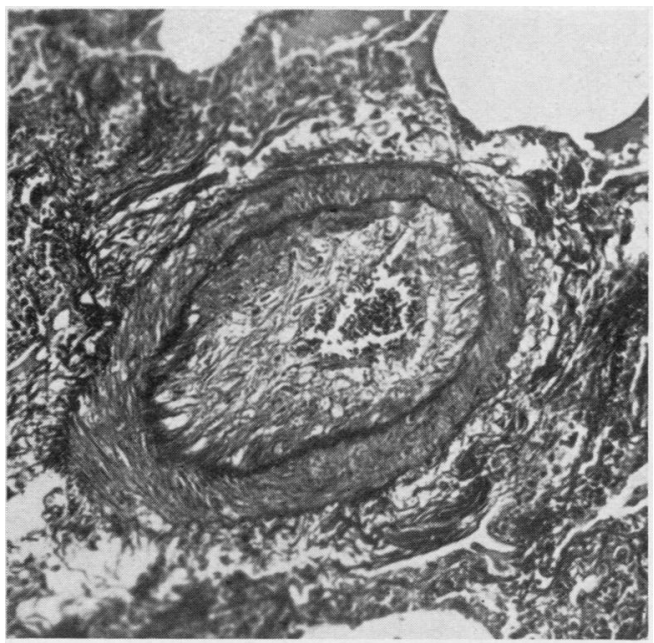

Fig. 7.-Recanalized pulmonary artery. Verhoeff-Van Gieson's stain $(\times 280)$

not present. There was no bronchitis or pneumonia, but collections of small round cells and plasma cells were common around dis=ased blood vessels.

Heart.-There was evidence of a healed LibmanSacks disease, affecting particularly the mitral cusps, which were partially calcified, but also the aortic and 
pulmonary valves. Slight endocardial fibrosis was present in all the chambers. The myocardium showed some interstitial fibrosis, also a few small fibrinoid foci and a mononuclear cell infiltration, mostly of plasma cells; similar lesions were found in the epicardium. Arterial and arteriolar fibrinoid or fibrous change was found rarely in retroperitoneal connective tissues, pancreas,ovary, stomach, spleen, adrenals, thyroid, skeletal muscles and kidneys. Slight glomerular hyalinosis was present in the latter.

Liver.-Severe centrilobular congestion and midzonal fatty change were seen.

Thyroid.-Glandular atrophy and fibrosis were conspicuous.

Kidneys.-Small collections of plasma cells and lymphocytes were observed in the kidneys, and also in the liver, ovaries, skeletal muscles, and skin.

Comment.-The most notable finding was the severity of the pulmonary vascular lesions.

Case 2, a 32-year-old spinster, was admitted to hospital in coma on 26.10.53. Loss of consciousness had been sudden, but for 2 days previously she had had severe frontal headache. A similar attack had occurred a year before, since when she had a permanent hemiplegia. Her health had otherwise been good and there was no obvious clinical manifestation of systemic collagen disease. She died a few hours after admission.

Post-mortem Examination (carried out 12 hours after death).-The main macroscopic findings were an active verrucous endocarditis of the aortic valve; extensive cerebral haemorrhage and also some porencephaly of the right precentral gyrus; pulmonary oedema; old renal and splenic infarcts; fatty liver. The right pleural sac was almost obliterated by dense fibrous adhesions. There were no pleural effusions. The lungs were markedly oedematous. No bronchial or vascular lesions were apparent.

Histology.-The diagnosis of active LibmanSacks disease was confirmed. Degenerative collagen changes, including fibrinoid lesions, were observed in the endocardium and myocardium, also in the liver. "Wire-loop" lesions were present in the renal glomeruli. Slight fibrinoid changes were found in occasional hepatic and intestinal veins, otherwise no vascular lesions were present. A variable degree of infiltration with large and small mononuclear cells, including plasma cells, was usual where there was degeneration of collagen. There were no skin lesions.

Widespread oedema was seen in the lungs, but no notable vascular changes. A small number of air sacs were lined by hyaline eosinophilic material, partly fibrinoid in character. There was also a minor degree of acute bronchopneumonia.

Comment.-There was severe oedema but no evidence of collagen disease in the lungs.

Case 3, a housewife, aged 33, was admitted to hospital on 1.3.48 with an erythematous rash of the face, malaise, pyrexia, and ulceration of the mouth. She had a history of colitis in 1934, pyelitis in 1936, and puerperal sepsis in 1943. In July, 1947, she had had joint pains of rheumatic type and in August, 1947, a "severe febrile cold". The rash on the face had first appeared in December, 1947.

Examination.-A diagnosis of acute disseminated lupus erythematosus was made. Rhonchi were heard in all areas of the chest.

Treatment.-Penicillin, sulphamezathine, neo-salvarsan, and bisglucol produced no improvement.

Progress.-Pyrexia continued and there was also persistent coughing. On 24.3.48 moist sounds were audible in the lung bases and bronchial breathing in the left base. Signs of congestive cardiac failure were $\vec{\circ}$ clearly manifest 4 days later and there was no response to treatment.

Death.-The patient died on 30.3.48.

Post-mortem Examination (carried out 20 hours ? after death).- An extensive scaly, erythematosus $\vec{G}$ eruption was present in the skin of the face and there $\rightarrow$ was superficial ulceration of the skin about the in right ear, also of the fingers and toes. Internally, there was an active verrucous endocarditis of the $\frac{}{\partial}$ tricuspid and mitral valves and dilatation of all the chambers of the heart. A small sero-fibrinous 3 effusion was present in the pericardial sac and there 을 were large, clear serous effusions in the pleural sacs. $\bar{\rho}$ Mucus or muco-pus was found in the larger bronchi. In the left lung the lower lobe was collapsed, while $\vec{c}$ in the right lung there were scattered areas of $\mathcal{G}$ collapse. Small ulcers were seen on the uvula and in the oesophagus. No ascites was present. The liver was enlarged and fatty, but the spleen was normal in size. The kidneys were enlarged and oedematous. There was a paucity of cortical lipoid in the adrenals. Some of the mesenteric lymph nodes were calcified.

Histology.-Degenerative collagen changes were found in the myocardium and endocardium. Fibrinous vegetations were attached to the affected parts of the mitral and tricuspid valves. Evidence of disseminated lupus erythematosus was apparent also in the skin and included fibrinoid thickening of arteries and arterioles. Elsewhere, vascular degen- 으 erative changes were seen only in a few small vessels $\bar{\sigma}$ in the myocardium and in a small minority of 3 hepatic veins. In the kidneys, the glomeruli were swollen and showed slight hyaline changes. Col- $\frac{0}{3}$ lections of mononuclear cells, including plasma cells, were present in tissues presenting degenerative 음 changes. Sections from the lower lobe of the left lung showed considerable collapse, though in $\frac{7}{0}$ sections from the left upper lobe of the right lung there were only occasional collapsed foci. The $\mathrm{N}$ cause of the collapse was not entirely clear, but $\sigma$ muco-pus was present in many of the bronchi, due $N$ to chronic bronchitis. Emphysema and some $\mathrm{N}$ oedema were also present. No notable vascular $\omega$ changes were observed in the lungs.

Comment.-The pulmonary lesion did not present any specific characteristics.

\section{Discussion}

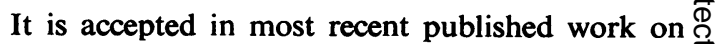
D.L.E. that, in some cases of the disease, changes $\frac{\mathbb{Q}}{\mathbb{Q}}$ 
occur in the lungs which cannot be explained by bacterial infection. There seems little agreement on the nature or incidence of the lesions and even less on their causation.

Klemperer and others (1941) were impressed by the contrast between the "long bouts of waxing and waning migrating bronchopneumonia" and the inconsiderable autopsy findings in the lungs. Such lesions as they found were considered "in no way specific".

Rakov and Taylor (1942) described an example of prolonged consolidation of lung due to "a chronic low grade interstitial pneumonitis". The affected lobes were "atelectatic", but there was no sign of bronchial obstruction.

Foldes (1946) found "chronic interstitial pneumonitis" with massive atelectasis in a case of D.L.E. where death was due to respiratory failure. Teilum (1946) described a "focal allergic pneumonia" in which there was fibrinoid change and histiocytic infiltration of the pulmonary connective tissues. Baggenstoss (1952), although of the opinion that there is no characteristic pulmonary parenchymal lesion, also encountered a case of "chronic interstitial atelectizing pneumonitis", with, in addition, "basophilic mucinous oedema of the alveolar walls". Harvey, Shulman, Tumulty, Conley, and Schoenrich (1954) considered that twenty of their 105 cases of D.L.E. had "lupus pneumonitis". Seven of the twenty came to autopsy and showed the following microscopic changes: hyaline alveolar membranes, focal necrosis of alveolar walls with capillary thrombi, areas of organizing interstitial pneumonia and haemorrhage, and "metaplasia of the bronchiolar epithelium".

There is some evidence that vascular lesions occur in the lungs in D.L.E. Over 20 years ago Baehr, Klemperer, and Schifrin (1935) reported an unusual degree of involvement of the vessels of the lesser circulation in four of a series of 23 autopsied cases of D.L.E. There was notable enlargement of the right heart in all four cases and three died in congestive cardiac failure. However, Klemperer and others (1941) found lesions of systemic implication in the small pulmonary arteries of only a single case among twenty autopsied. Wood (1952), in an account of pulmonary hypertension, included D.L.E. as a cause. Ellman and Cudkowicz (1954), in a review of the pulmonary lesions in the diffuse collagen diseases, have put forward the view that "the lung changes in this disease group may represent the effects of progressive pulmonary ischaemia resulting from the loss of a bronchial arterial blood supply".

Tumulty and Harvey (1949) described infiltration of the lungs in three autopsied cases of D.L.E. as "typical of the changes seen in rheumatic fever, periarteritis nodosa, and sulphonamide hypersensitivity".

There is a notable similarity between the description by Thorell (1952) of the radiological findings in cases of D.L.E. with pulmonary and pleural involvement and those met in pulmonary infarction (Macleod and Grant, 1954). Thorell described small, bilateral pleural effusions and pleural thickenings, often accompanied by parenchymal changes, commonly subpleural and basal in situation.

Only in our Case 1 could we identify morphological changes of distinctive character in the lungs. The severe degenerative and fibrotic pulmonary vascular changes were clearly similar to those found in other parts of the body and seemed to be the result of the disease process affecting the vessel walls. The obstruction to the blood flow to the lungs, caused in this way, led to hypertrophy of the right ventricle, detected by electrocardiogram and confirmed at autopsy. Physical signs in the lungs were ill-defined and difficult to interpret. Breathlessness, however, was severe and from time to time there was evidence, especially radiological, of pulmonary infarction. It seems probable that, although the fully developed picture of cor pulmonale occurs in a minority of cases of D.L.E., the pulmonary vessels may be involved more often than has been realized. It may be that some of the ill-defined lesions which are found in the lungs clinically, radiologically, and at post-mortem, are the result of occlusive changes in the lung vessels.

The reason for the peculiar concentration of vascular lesions in the lungs of Case 1 and the absence of such changes in our other two cases of D.L.E. is not known.

\section{Summary}

A description is given of the changes found in the lungs of three female patients, aged 43,32 and 33 years, who presented the essential manifestations of disseminated lupus erythematosus.

In the oldest patient there were widespread degenerative and fibrous changes in the smaller pulmonary arteries and arterioles. In the other two patients there were no specific lung lesions.

Brief reference is made to the literature on the subject of lung changes in disseminated lupus erythematosus.

We are grateful to Dr. R. J. Duthie and Prof. J. S. Young for permission to publish these cases and for helpful advice and criticism. 


\section{REFERENCES}

Baehr, G., Klemperer, P., and Schifrin, A. (1935). Trans. Ass. Amer. Phys., 50, 139.

Baggenstoss, A, H. (1952). Proc. Mayo Clin, $27,412$.

Bllman, P., and Cudkowicz, L (1954). Thorax, $9,46$.

Ellman, P., and Cudkowicz, L. (1954). Thorax,
Foldes, J. (1946). Amer. J. clin. Path., 16, 160.

Harvey, A. McG., Shulman, L. E., Tumulty, P. A., Conley, C. L., and Schoenrich, E. H. (1954). Medicine (Baltimore), 33, 291.

Kaposi, M. K. (1872). Arch. Derm. Syph. (Wien), 4, 36.

Klemperer, P., Pollack, A. D., and Baehr, G. (1941). Arch. Path. (Chicago), 32, 569.

Macleod, J. G., and Grant, I. W. B. (1954). Thorax, 9, 71.

Osler, W. (1904). Amer. J. med. Sci., 127, 1

Rakov, H. L., and Taylor, J. S. (1942). Arch. intern. Med., 70, 88

Teilum, G. (1946). Acta med. scand., 123, 126.

Thorell, I. (1952). Acta radiol. (Stockh.), 37, 8 .

Tumulty, P. A., and Harvey, A. McG. (1949). Bull. Johns Hopk. Hosp., 85, 47.

Wood, P. (1952). Brit. med. Bull., 8, 348.

\section{Altérations pulmonaires dans le lupus érythémateux disséminé \\ RÉSUMÉ}

On décrit les altérations pulmonaires chez trois femmes de 43,32 et 33 ans présentant les manifestations essentielles du lupus érythémateux disséminé.
Chez la plus vieille des trois malades il y eut des lésions fibreuses et de dégénérescence étendues dans les artères pulmonaires secondaires et dans les artérioles. Chez les deux autres on ne trouva pas de lésions pulmonaires spécífiques.

On mentionne brèvement la littérature sur les lésions pulmonaires dans le lupus érythémateux disséminé.

\section{Alteraciones pulmonares en el lupus eritematoso diseminado}

\section{SUMARIO}

Se describen las alteraciones pulmonares en tres enfermas de 43, 32 y 33 años presentando manifestaciones esenciales de lupus eritematoso diseminado.

En la mujer de 43 encontráronse extensas lesiones fibrosas y degenerativas en las arterias pulmonares secundarias y en las arteriolas. En las demás no hubo lesiones pulmonares especificas.

Se menciona brevemente la literatura sobre lesiones pulmonares en el lupus eritematoso diseminado. 